\title{
Application of Impact Vibration Test Method for Bridge Substructure Evaluation
}

\author{
Pham Hoang Kien ${ }^{1, *}$ \\ ${ }^{1}$ University of Transport and Communications, Faculty of Civil Engineering, Hanoi, Vietnam
}

\begin{abstract}
The bridge foundations are constructed mainly below ground or water level. The rehabilitation of a foundation is difficult, and the results of evaluation of structural conditions are usually inaccurate. Furthermore, there are many cases that after natural disasters such as earthquakes, typhoons and floods, it is required to rapidly evaluate bridge substructure conditions for a judging decision on being able to open the bridge to traffic or not. Impact vibration test method has been developed to deal with such problems. Impact vibration test method is a non-destructive dynamic test method which allows to evaluate structural conditions of bridge substructures promptly with a good soundness. In this study, firstly, impact vibration test method, which is one of the utilizable non-destructive tests on the scouring of bridge substructure, is presented. Then, application of the test method for substructure evaluation of a bridge in Vietnam is introduced. The soundness and effectiveness of test method is also discussed.
\end{abstract}

\section{Introduction}

A bridge substructure is designed to resist vertical settlement resulting from dead and live loads, and lateral movement and rotation caused by temperature change, friction, wind, water, and seismic loads. The bridge substructure and its connection to the footing must resist moments, shear, and compressive forces. The footing must resist lateral, vertical, and rotational movements. The bridge substructure condition rating is governed by the condition of its structure and the dimension and type of footing (shallow, deep, or combined). Deformation and damage of substructure and its foundation will greatly affect traffic service and safety. There are three (3) major phenomena of substructure foundation damage, namely, settlement, inclination and scour. Among these, scour is considered as the most common cause of bridge substructure failure. Scour occurs progressively as supporting material under a footing is removed during flood events and is replaced with material that has little or no bearing capacity.

Accurate information on a bridge substructure is an essential part of implementing a cost effective and safety-conscious bridge management. Substructure foundations are constructed mainly below ground or water level, therefore, visual inspection is very difficult. Dynamic testing is considered to play a key role in bridge substructure performance evaluation and

\footnotetext{
* Corresponding author: phkien@utc.edu.vn
} 
monitoring system as it can provide more accurate information on the condition, type, and vulnerability of bridge substructures that cannot be obtained by normal visual surveys.

Soundness condition of a bridge substructures can be evaluated on the basis of dynamic settlement, frequency and amplification of vibration excited by passage of vehicle truck or train, in addition to the static measurement of inclination or settlement of the bridge substructure. If the above measuring results exceed the allowable values or show unfavorable time-dependent tendency, the performance of the bridge substructures is suspected. However, the above measuring results generally depend on the weight and passing velocity of the vehicle truck or train; therefore the measuring results vary widely and are insufficient to evaluate the soundness condition of the bridge substructures. Furthermore, there are many cases that after natural disasters such as earthquakes, typhoons and floods, it is required to rapidly evaluate bridge substructure conditions for a judging decision on being able to open the bridge to traffic or not. Impact vibration test method has been developed to deal with such problems. Impact vibration test method is a non-destructive dynamic test method which allows to evaluate structural conditions of bridge substructures promptly with a good soundness. In this study, firstly, impact vibration test method, which is one of the utilizable non-destructive tests on the scour of bridge substructure, is presented. Then, application of the test method for substructure evaluation of a bridge in Vietnam is introduced. The soundness and effectiveness of test method is also discussed.

\section{Bridge substructure evaluation by impact vibration test}

For bridge substructure inspection and evaluation, the major items to be inspected are: settlement, horizontal movement, inclination and scour. In the past, the item of scour was not included in periodical substructure inspection even if the progress of damage due to scour could be confirmed from inspection results. However, recently, the importance of periodical inspection on scour during/after a heavy rain or flood has been recognized. Damage to substructure by scour is a kind of damage difficult to visually predict. Once it occurs, it often leads to serious accident and disruption of transport. One method developed to evaluate the soundness of bridge pier is using the natural frequency obtained by impact vibration tests. This method uses the tendency for the natural frequency of a pier to decrease as phenomena such as scour deteriorate the soundness of that foundation's pier. The natural frequencies of bridge pier are determined by the mass of superstructures and bridge pier, the stiffness coefficient of bridge pier and the soil characteristics of the ground.

The impact vibration test makes use of the difference of natural frequencies when the scour occurs and riverbed elevation around the bridge pier has changed.

\subsection{Procedure of impact vibration test}

The impact vibration test procedure is shown in Fig. 1. Firstly, the bridge pier is hit with an iron ball suspended from the superstructure. The response acceleration and velocity are then measured. An iron ball with the weight of around $30 \mathrm{~kg}-50 \mathrm{~kg}$ is usually selected for practical reason of workability. To obtain a clear response and reduce noises, iron ball hitting is repeated around five times, because the response acceleration and velocity are quite small with a light weight. Accelerometers can be set at three locations along the bridge pier for the evaluation of vibration modes.

Secondly, the measurement results of impact vibration test are processed and analyzed. The obtained time history response waves are transformed by Fast Fourier transformation to obtain the Fourier Spectrum. Natural frequencies of bridge pier are determined by the result of the Fourier Spectrum and Phase Spectrum. 
Fig. 2 gives a comparison between the Fourier Spectrum obtained from impact vibration test and the vibration generator test for the same bridge pier. There is a good agreement between results of two test methods, and it can be said that the Fourier Spectrum obtained from impact vibration test is useful to obtain the natural frequency of bridge piers.

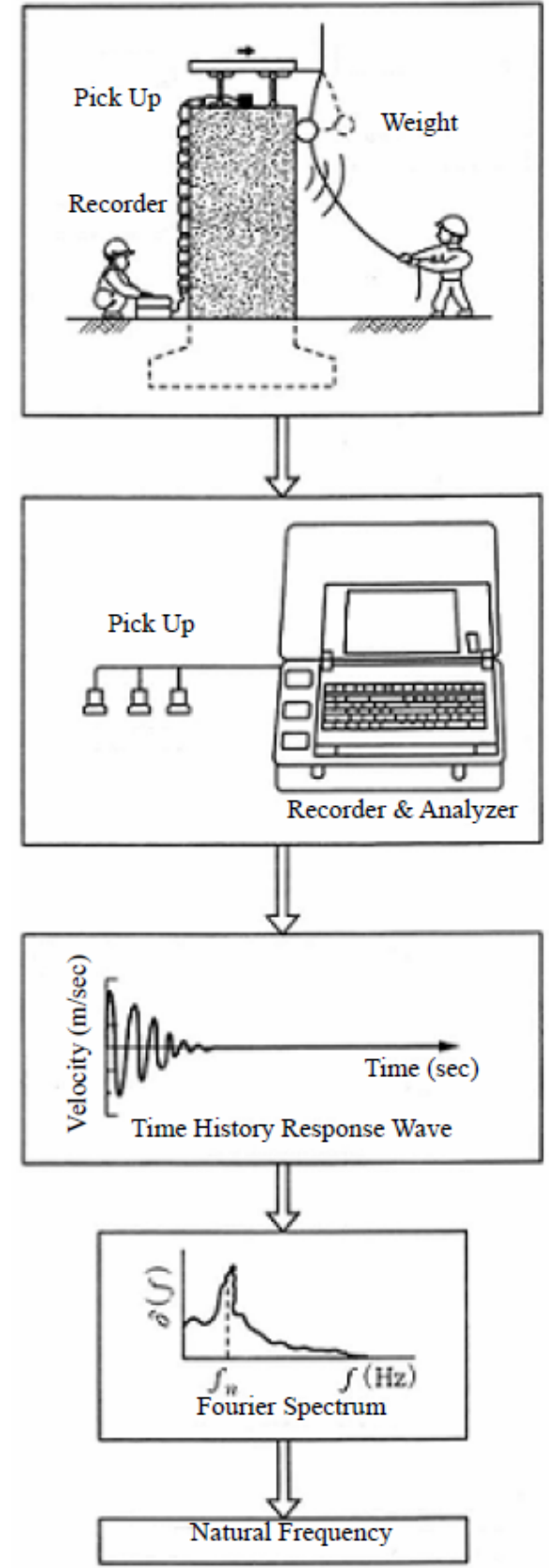

Fig. 1. Procedure of impact vibration test

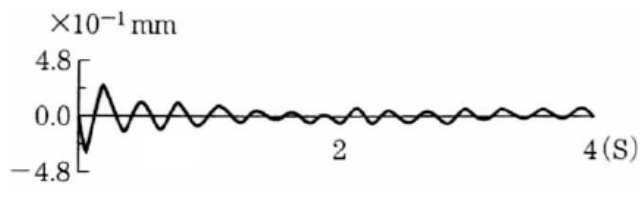

(a) Percussive Vibration Wave

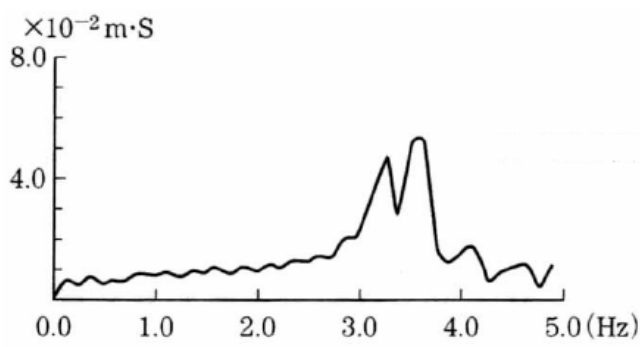

(b) Fourier Spectrum by Impact Vibration Test

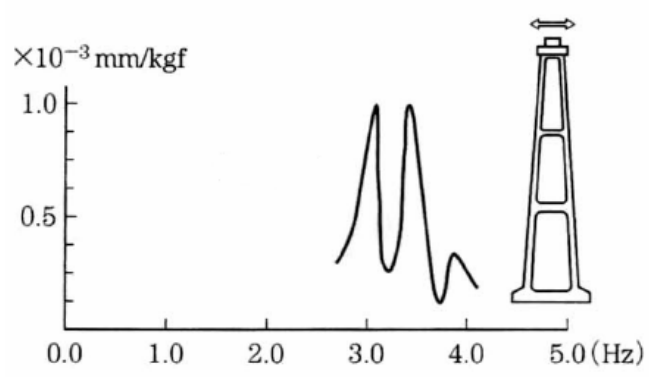

(c) Fourier Spectrum by Vibration Generator Test

Fig. 2. Comparison between impact vibration test and vibration generator test 


\subsection{Soundness evaluation of bridge pier}

The soundness of bridge pier can be evaluated by comparison of natural frequency obtained from impact vibration test to a standard value. The formula for index of soundness which is defined as the ratio of measured natural frequency to the standard value, is given in Equation (1).

$$
\alpha=\frac{F_{m}}{F_{s}}
$$

where $\alpha$ is index of soundness, $F_{m}$ and $F_{s}$ are measured natural frequency and standard value of natural frequency, respectively.

An evaluation criteria for the index of soundness is proposed by Railway Technical Research Institute (RTRI), Japan as shown in Table 1.

Table 1. Soundness evaluation criteria

\begin{tabular}{|c|c|c|l|}
\hline $\begin{array}{c}\text { Index of } \\
\text { soundness } \alpha\end{array}$ & \multicolumn{2}{|c|}{$\begin{array}{c}\text { Evaluation } \\
\text { rank }\end{array}$} & \multicolumn{1}{c|}{ Countermeasure } \\
\hline$\alpha \leq 0.70$ & \multirow{2}{*}{ A } & A1 & $\begin{array}{l}\text { Dangerous state can occur under the action of extreme } \\
\text { loads. Other investigation is required and reinforcement } \\
\text { should be performed. }\end{array}$ \\
\cline { 4 - 4 } $0.70<\alpha \leq 0.85$ & A2 & $\begin{array}{l}\text { Natural frequency deterioration should be continuously } \\
\text { confirmed. }\end{array}$ \\
\hline $0.85<\alpha \leq 1.00$ & \multicolumn{2}{|c|}{$\mathrm{B}$} & There is almost no problem at present stage \\
\hline $1.00<\alpha$ & \multicolumn{2}{|c|}{$\mathrm{S}$} & The structure is completely sound at present stage \\
\hline
\end{tabular}

In case where the natural frequency of bridge pier was obtained by measurement immediately after bridge construction, this initial value can be taken as the standard value of natural frequency, and a quantitative evaluation of the foundation's bearing capacity or the degree of deterioration in the pier can be accurately carried out by comparing the standard value with the frequency obtained at the time of evaluation. However, in reality, the initial value is rarely available. Previously measured value of natural frequency can also be taken as standard value.

RTRI (Railway Technical Research Institute, Japan) also proposed an experimental formula to calculate the standard value of natural frequency by the regression analysis on the basis of many field data. RTRI implemented a large number of impact vibration tests on piers which had been judged to be clearly sound as a result of detailed visual inspection, dynamic displacement measurements carried out when trains were passing and so on. Then the accumulated field data were statistically processed with regression analysis considering parameters which are highly sensitive on the natural frequency of bridge pier such as the weight of superstructure and height of the pier. The proposed formula shows a high correlation coefficient, indicating an accurate estimation.

In case where the information of bridge pier can be obtained from design documentations, the standard value of natural frequency can be evaluated by Eigenvalue analysis of bridge pier structure. For this analysis, the reaction forces of the ground are expressed as spring constants. The actual reaction forces are not elastic and they are not modeled as a spring. However, for practical reasons, it may be treated as an elastic spring model because of small deformation. 


\section{Case history}

\subsection{Outline of the test}

Impact vibration tests were carried out for two piers (pier P4 and P5) of an old bridge in Haiphong city, a port city and the third largest city of Vietnam with a population of over two million people. The Bridge over Lach Tray river on a major urban route connecting city center to suburban areas was constructed in 1980 as shown in Fig. 3. As the old Bridge could not satisfy the increasing demand of traffic volume, it was decided that the bridge superstructure would be destructed and be replaced by a new one. However, two piers (pier P4 and P5) of the old Bridge were decided to be reused. As pier P4 and P5 have been under service with high traffic volume and river discharge for more than 35 years, it is necessary to evaluate their soundness condition to confirm the reuse possibility of these two piers.

Fig. 4 shows the overview of bridge piers after deduction of the old superstructure. Setting work for impact vibration test is shown in Fig. 5. The tests were carried out for both direction of bridge axis and direction perpendicular to bridge axis.

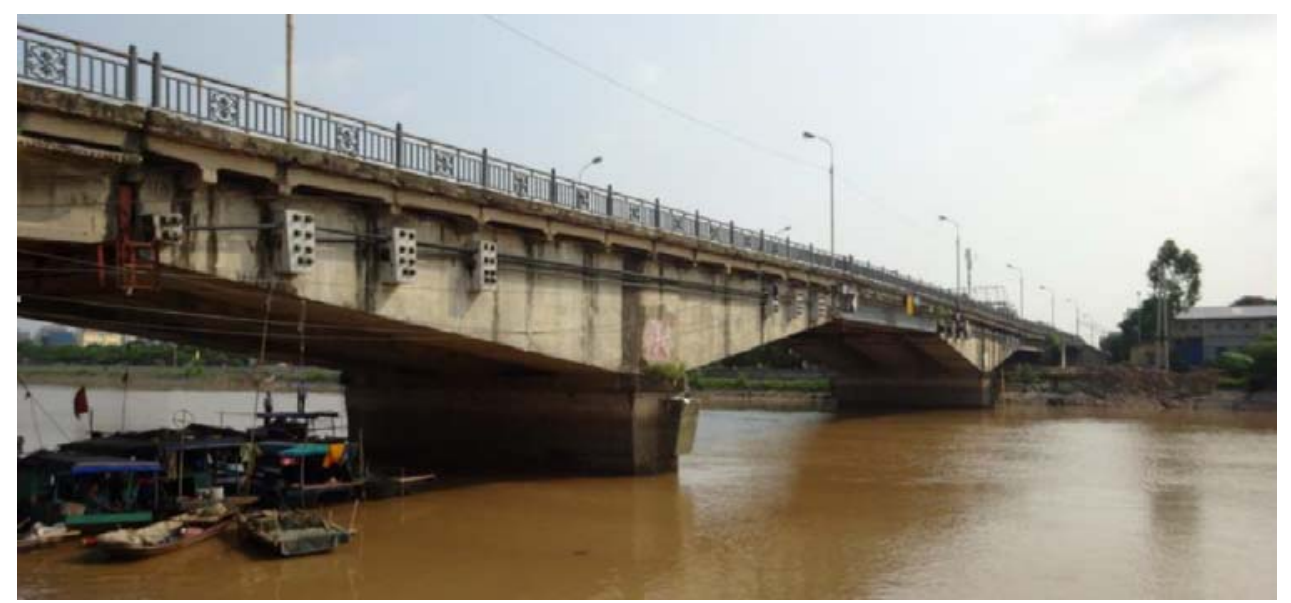

Fig.3. Overview of the Bridge over the Lach Tray river (before deduction of old superstructure)

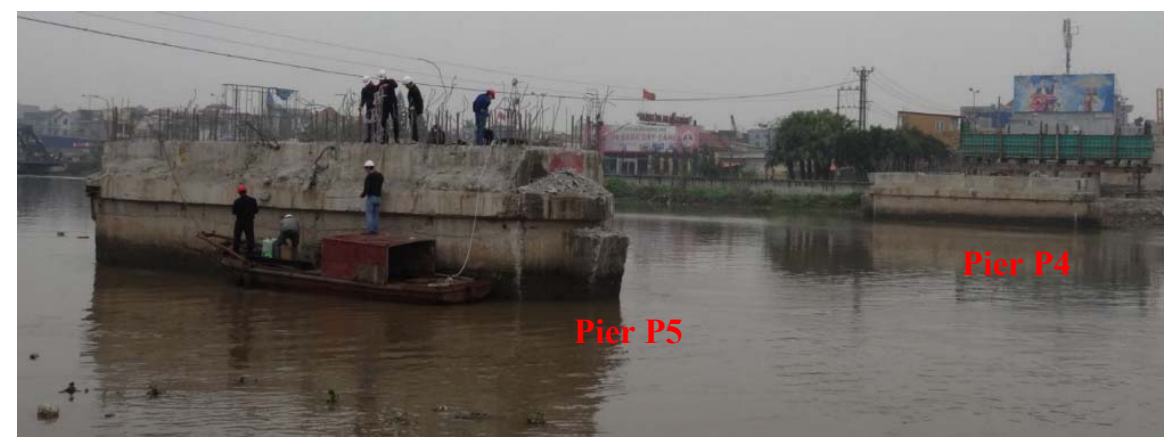

Fig.4. Overview of bridge piers (after deduction of old superstructure) 


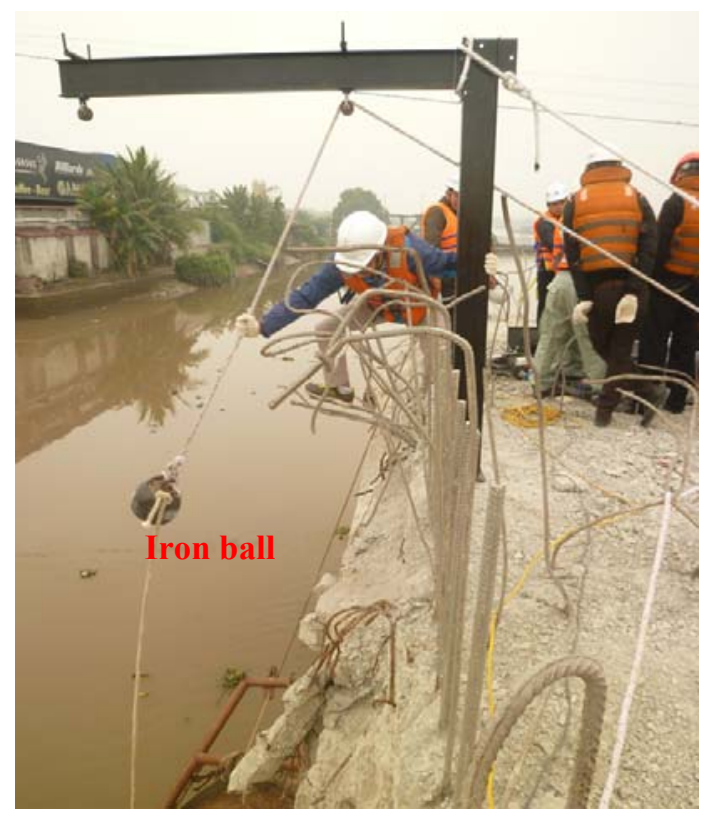

Fig.5. Setting work for impact vibration test

\subsection{Soundness evaluation of pier P4 and P5}

Fig. 6 and Fig. 7 shows a time history of acceleration measured from impact vibration test of pier P4 and P5 subjected to the impact force using $40 \mathrm{~kg}$ iron ball. From the measured time history, spectral analysis was carried out to identify the natural frequency. Fourier and phase spectrums of pier P4 and P5 are also shown in Fig. 6 and Fig. 7, respectively.

The standard values of natural frequency of pier P4 and P5 were evaluated by Eigenvalue analysis of the pier structure. Before implementing impact vibration test, geotechnical investigation was carried out and the spring constants which express the interaction between ground and pier foundation piles were calculated based on this geotechnical investigation results. Analytical structural model of bridge pier for Eigenvalue analysis is shown in Fig. 8 . Results of soundness evaluation of pier P4 and P5 are shown in Table 2. Based on evaluation results, the judgment of reuse of these two piers was made.

However, for pier P4 in the direction perpendicular to bridge axis, the soundness index $\alpha$ is rather low and it is recommended to continuously confirm natural frequency deterioration in the future. 


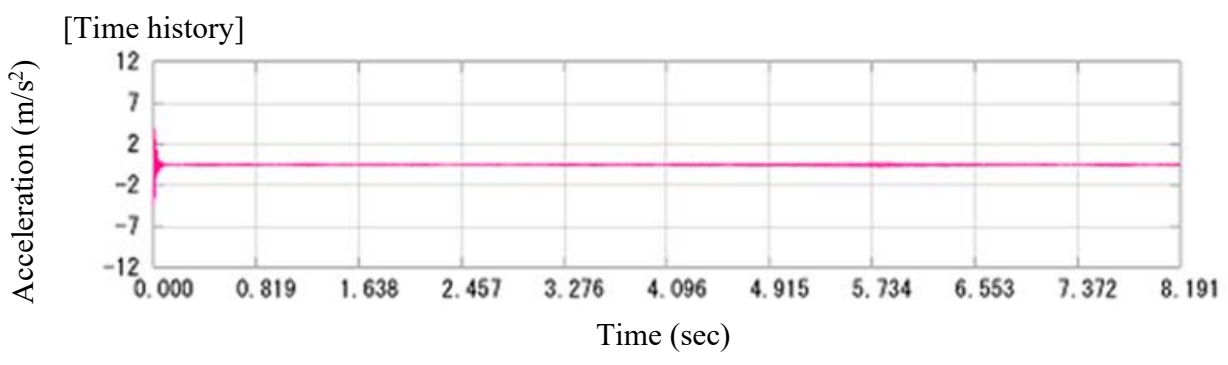

[Fourier spectrum]

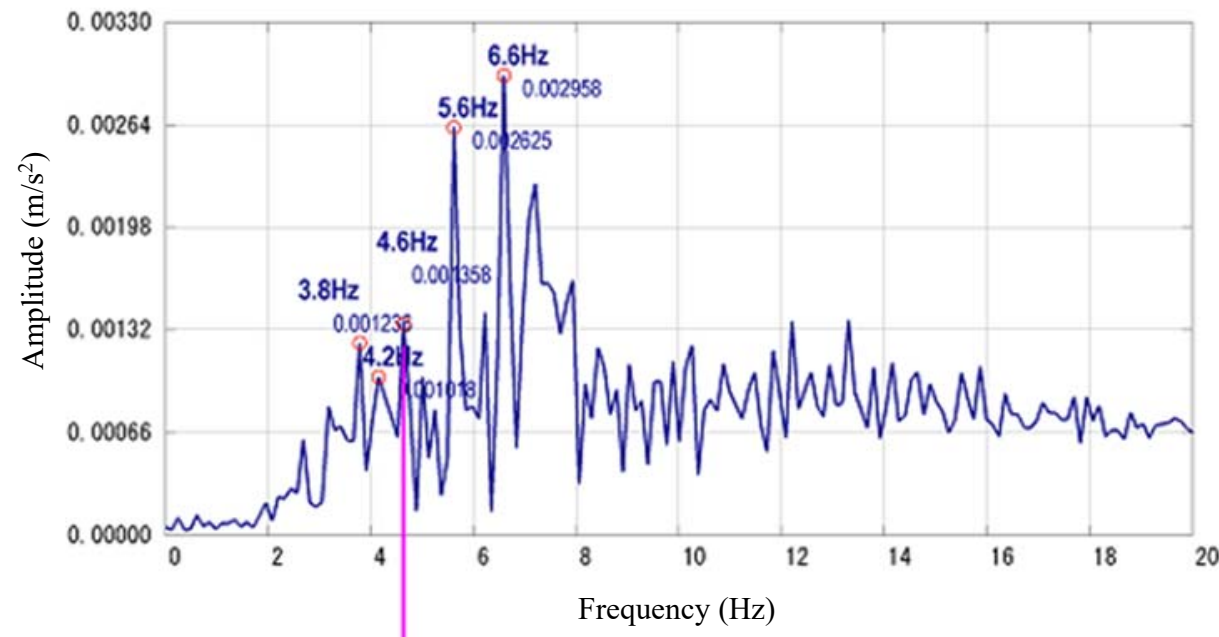

[Phase spectrum]

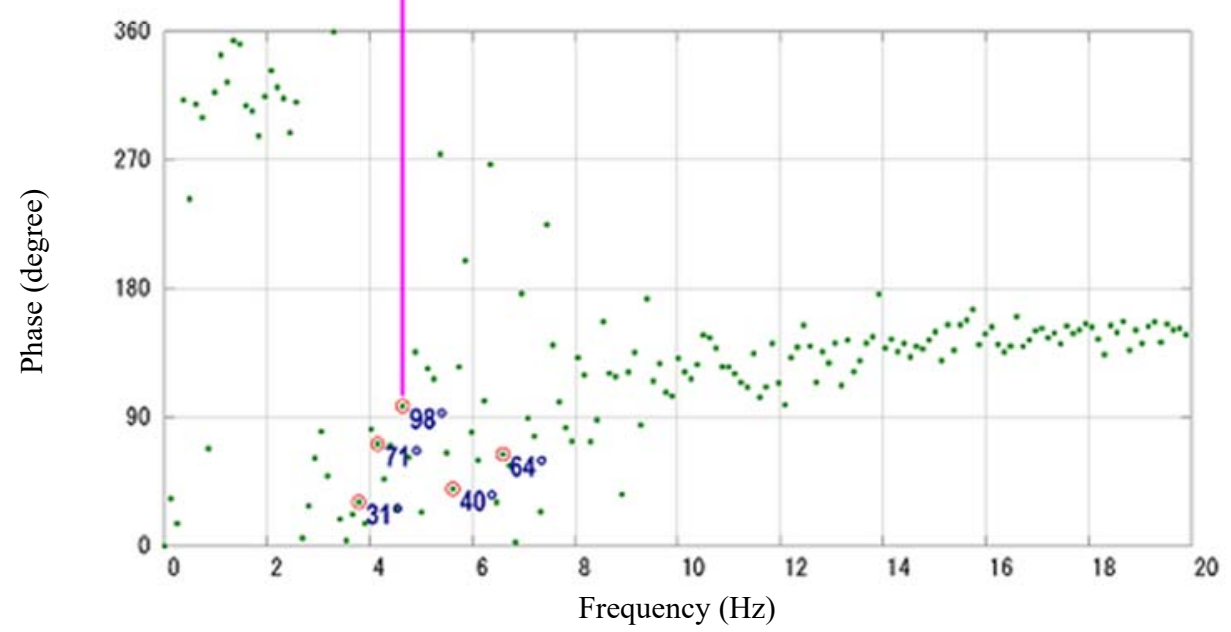

Fig.6. Results of impact vibration test of pier P4 (for direction of bridge axis) 


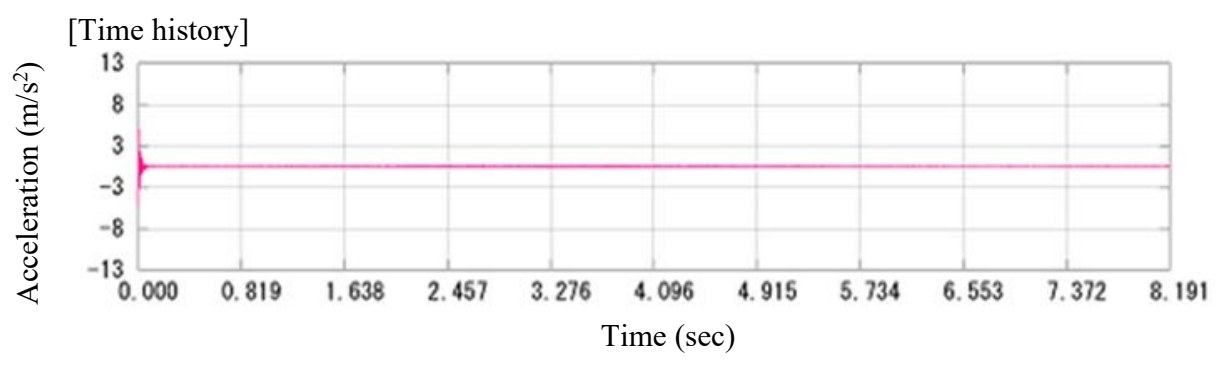

[Fourier spectrum]

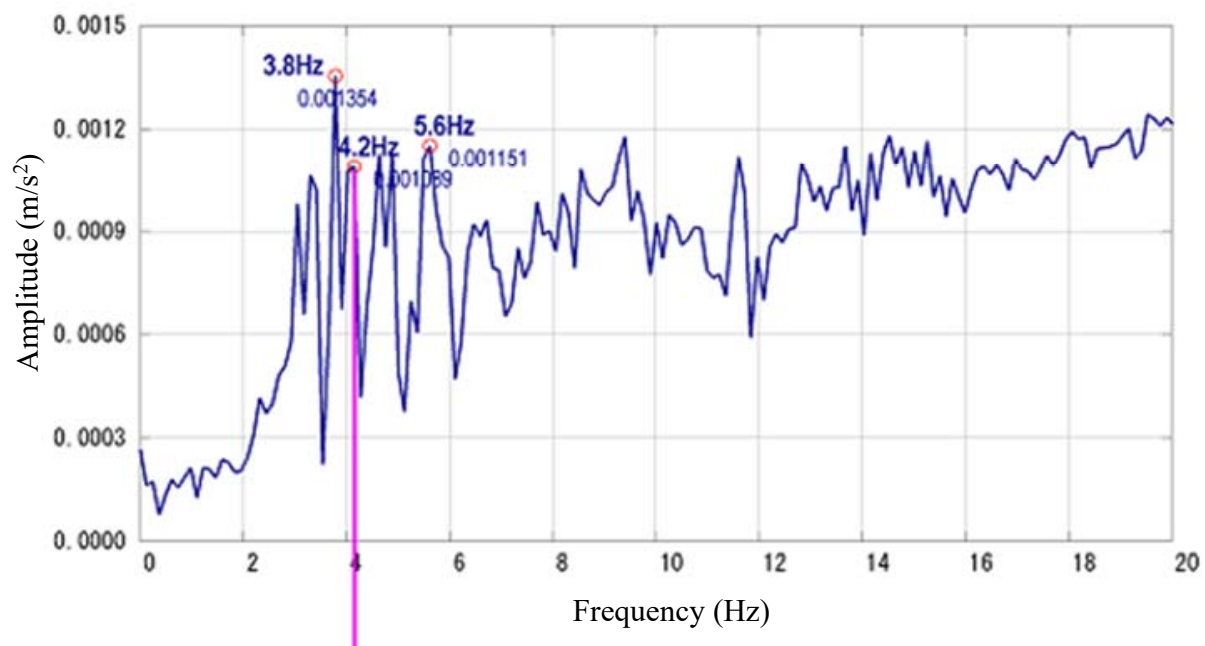

[Phase spectrum]

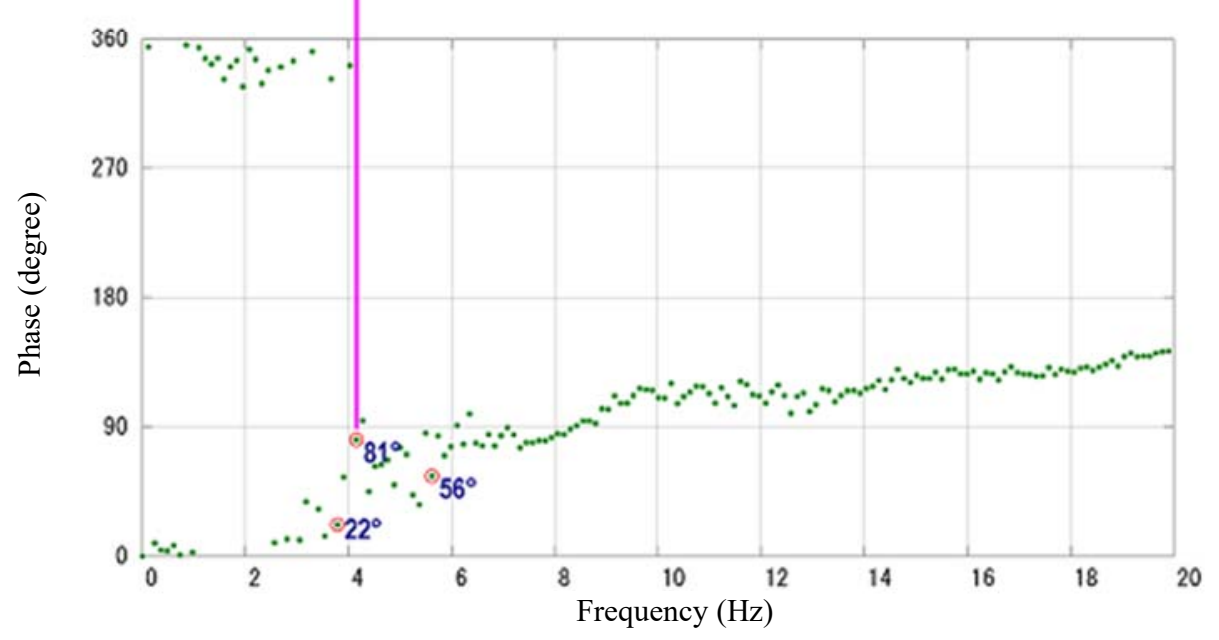

Fig.7. Results of impact vibration test of pier P5 (for direction of bridge axis) 


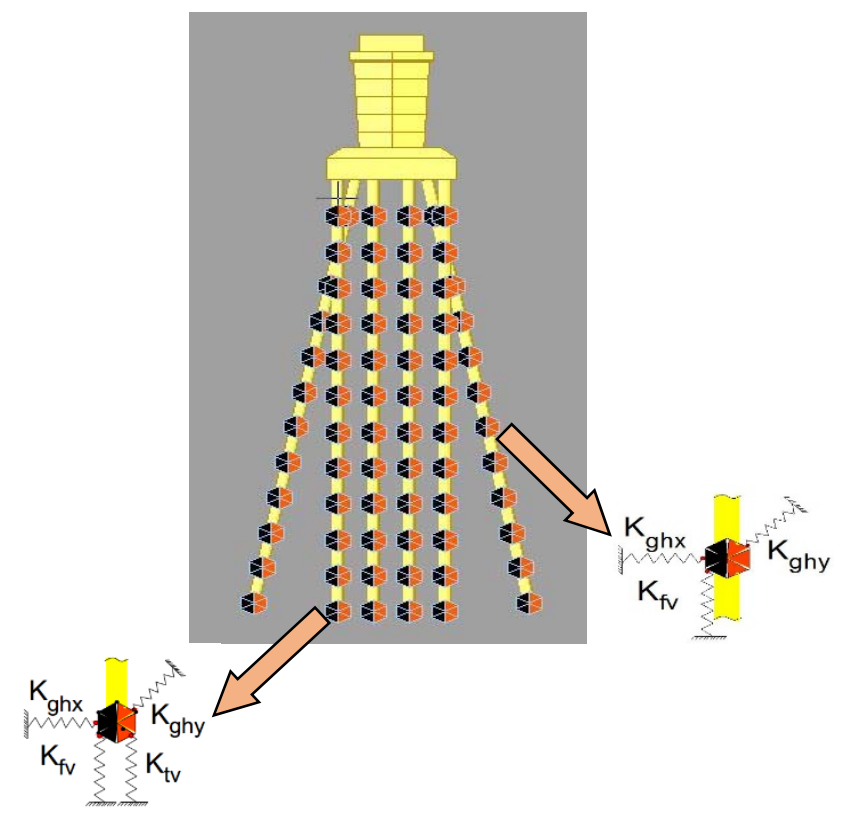

Fig.8. Analytical structural model for Eigenvalue analysis

Table 2. Results of soundness evaluation of pier P4 and P5

\begin{tabular}{|l|l|c|c|c|c|}
\hline \multicolumn{2}{|c|}{} & \multicolumn{2}{|c|}{ Pier P4 } & \multicolumn{2}{c|}{ Pier P5 } \\
\cline { 3 - 6 } & & $\begin{array}{c}\text { Direction } \\
\text { perpendicular to } \\
\text { the bridge axis }\end{array}$ & $\begin{array}{c}\text { Direction } \\
\text { of bridge } \\
\text { axis }\end{array}$ & $\begin{array}{c}\text { Direction } \\
\text { perpendicular to } \\
\text { the bridge axis }\end{array}$ & $\begin{array}{c}\text { Direction } \\
\text { of bridge } \\
\text { axis }\end{array}$ \\
\hline $\begin{array}{l}\text { Natural } \\
\text { frequency }\end{array}$ & Measured results & 3.9 & 4.6 & 4.8 & 4.2 \\
\cline { 2 - 6 } & Standard value & 5.40 & 5.39 & 4.27 & 4.37 \\
\hline $\begin{array}{l}\text { Soundness } \\
\text { evaluation }\end{array}$ & Soundness index $\alpha$ & 0.72 & 0.853 & 1.12 & 0.96 \\
\cline { 2 - 6 } & Evaluation rank & A2 & B & S & B \\
\hline
\end{tabular}

\section{Conclusion}

The paper describes a practical technique to evaluate the soundness of bridge substructure by using the impact vibration test. Impact vibration test is one of the utilizable non-destructive dynamic test on the scour of bridge substructure as the test makes use of the difference of natural frequencies when the scour occurs and riverbed elevation around the bridge pier has changed. In order to estimate the measured natural frequency of bridge substructure, a spectrum analysis was conducted with a time history of the free vibration obtained from measurement data. Then the measured natural frequency is compared to a standard value to evaluate the soundness of bridge substructure. Application of the test method for substructure evaluation of two old bridge piers in Vietnam is introduced as a case study. Method to evaluate the standard value of natural frequencies by Eigenvalue analysis of analytical structural model is described in the case study. The application results show that impact vibration test has an advantage of nondestructive, quick and accurate evaluation.

\section{References}

1. A. Nishimura, S. Tanamura, RTRI report, A study on integrity assessment of railway bridge foundation, Vol. 3(8), 41-49 (1989). 
2. Railway Technical Research Institute, Design standard for railway earth structure (in japanese), Maruzen (2000).

3. N. Kobayashi, M. Shimamura, JR East technical review (Japanese version), Development of a scour monitoring method for piers, No.3, 49-52 (2003).

4. T. Sakata, T. Tsuchida, A. Okazaki, First Japan-Vietnam workshop on urban infrastructure system and transportation, Life cycle management of bridges and structures, 116-128 (2004).

5. S. Watanabe, M. Samizo, A. Fuchiwaki, T. Sugiyama, RTRI report, Evaluation of the structural integrity of bridge pier foundation under flood condition by the natural frequency measured with a micro-tremor, Vol. 21(1), 31-36 (2007).

6. M. Shinoda, H. Haya, S. Murata, Fourth International Conference on Scour and Erosion 2008 , Nondestructive evaluation of railway bridge substructure by percussion test, 285 290 (2008).

7. P. H. Kien, T. Sakata, A. Nishimura, 40 Years of Cooperation between Vietnam and Japan in Construction Sector: Achievements and Opportunities, Structural health evaluation for bridge substructures by impact vibration test method, 281-290 (2013). 